\title{
Öteki Olanın Temsili: Ruud Van Empel'ın Egzotik Dünyası
}

Dr. Öğr. Üyesi Burcu Günay Kaygusuz

Makale Geliş Tarihi: 16.01.2018 Yayına Kabul Tarihi: 04.02.2018

\section{Özet}

Sonsuz çeşitliliği ve güzelliği ile var olan bitki evren, uygarlık tarihi boyunca insanoğlunu da kendisine hayran bırakmıstır. Bu araștırma bitki evrenden bir gösterge olarak seçilen lotus çiçeğinin, mitler ile başlayan anlam yolculuğunu ve sanatta temsil boyutunu irdeleme düš̈üncesini taşımaktadır. Bu ile başlayan anlam yolculuğunu ve sanatta temsil boyutunu irdeleme duş̧uncesini taşımaktadır. Bu
doğrultuda ilk olarak özellikle Doğu felsefesinde geniş yer tutan lotus ya da nilüfer çiçeğinin botanik tanımı ve onun sembolleşmesine yön veren parametreler ortaya konulmuştur. Ardındaki süreçte, birçok kültürde sonsuzluk, temizlik, bereket, ölüm/yeniden doğum gibi kavramlar atfedilen bu çiçeğin, mitlerden başlayarak günümüz sanatına uzanan seyri, çağdaş sanatçı Ruud Van Empel'in kurguladığı egzotik doğa üzerinden sorgulanmıştır. Bu araştırma Doğu kültüründe bir gösterge olarak yer alan lotusu, Batılı bir sanatçının bakış açısından irdeleme düşüuncesini taşımaktadır. Bu çalış̧a kapsamında, bir çiçeğin kültürel kodlamaları belirtilerek, onun günümüz sanatındaki yeri tek bir sanatçının eserleri üzerinden tarihsel (literatür tarama) yöntem kullanılarak açıklanacaktır.

Anahtar Kelimeler: Bitki Evren, Temsil, Lotus, Öteki, Ruud Van Empel.

THE PRESENTATION OF OTHER: THE EXOTIC WORLD OF RUUD VAN EMPEL

\section{Abstract}

The plant universe, with its infinite variety and beauty, admires human beings throughout the history of civilization. This research carries the idea that the lotus flower being selected as an indicator in the plant phase, the meaning journey starting with the myths and the representation dimension in art. In this direction, firstly botanical definition of lotus or lotus flower which has a wide place especially in Eastern philosophy and parameters which direct its symbolization have been put forward. In the process that followed, the flow of this flower, from myths to contemporary art, was questioned through the exotic nature of the contemporary artist Ruud Van Empel, attributed to concepts such as eternity, cleanliness, fertility, death / rebirth in many cultures. This research, as an indicator in Eastern culture, carries the thought of deliberation from the point of view of a Western artist. In this study, by specifiying the cultural coding of a flower, its place in contemporary art will be explained using the historical (literature review) method through the works of a single artist.

Keywords: Plant Universe, Presentation, Lotus, Other, Ruud Van Empel 


\section{Giriş}

Doğa, varolduğu zaman diliminden itibaren, sınırız bir yaşam çeşitliliği ile sürekli devinim haline sahiptir. Doğanın bir parçası olan bitki evren de bakan kişide derin bir hayranlık ve dinginlik düşüncesi uyandırır. Çin'de minyatür bahçelerinin düzenini kaleme alan bir yazar "doğaya bakma sevgisi gibi genellemelerin pek çok uygarlıkta ortak olduğunu dolayısıyla herhangi bir tekil uygarlığa izafe edilebilecek özgül bir durumdan bahsedilemeyeceğini ifade eder (Stein, 1990: 49). Bunun en belirgin nedeni ise bitki evren içerisinde yer alan tüm canlıların kültürün bir parçası olmasından ötürüdür. Bu durumu Çiçeklerin Kültürü'nde Jack Goody şu sözleri ile ifade eder: "Çiçekleri ve bitkileri evcilleştirip yetiştirilebilir kılan insanoğlu, toplumsal yaşam içinde onları kullanır, hepsinden önemlisi ölüler, canlılar, ilahi varlıklar ve insanlarla ilişki kurmada, sürdürmekte ve sona erdirmekte hayatımıza anlam katttıkları için bitki evren kültürlenme sürecimizin bir parçasıdır" (Goody, 2010: 26). Bu saydığımız özelliklerden dolayı geçmişten itibaren estetik ve yaşam değerinin yanında, bitki evrene yalnızca dünyevi olanda değil, uhrevi yaşamda da özellikler atfedilmiştir.

Bitki evrenin uhrevi dünyadaki temsillerinden ilki nadide çiçeklerle donatılan Cennet Bahçesi inancıdır. Özellikle Doğu Felsefesi'nde yer alan ve ardından dinsel inanç düzeyine yükselen Cennet Bahçesi için, MayerTasch Kur'an'dan alıntı yaparak "vaha özlemi ile yanan ve yüce tanrının lütfuna ermiş olan çöl evlatları için, sonsuz hazlarla dolu bahçeler sunulur" (Sarkowicz, 2003: 11) ifadesi ile bitki evrenin insanlık için bir ödül ve arzulanan son nokta olduğunu gösterir. Kutsal kitaplarda yer aldığı gibi insanın kültürlenme sürecinin bir göstergesi olan bitkiler, sonsuz yaşam sembolü olarak adlandırılır.

Bitki evrene yüklenen anlam bir gelenek silsilesi ile ilerlerken onun içinde bazıları, diğerlerinden daha kutsal görülmüş olup, bu boyutuyla da sanatta temsil boyutu kazanmışlardır. Sanat tarihinin belli dönemlerinde (Hıristiyan Ortaçağ resimleri gibi) çiçeklerin yaptığı metaforik çağrışımlar nedeniyle, onlara alegorik olarakyaklaşılmıştır. Örneğin, "metaforik konulu resimlerde, rengi saflı̆ı̆ın göstergesi olan beyaz zambak; manevi bir gösterge olarak; Bakire Meryem'i temsil ederken, gül ise seküler aşkı ve cenneti anımsatır" (Wheelock, 1961: 17). Bu saydığımız örnekler gibi çamurlu bir ortamda yetişmesine rağmen kendisini sürekli temiz kılmasını sağlayan çeperleri ile lotus, Doğu Felsefesi'nde kutsal kabul edilen ve temsil boyutu olan bir çiçektir.

\section{Lotus ve Mitlerdeki Temsiliyeti}

Lotusun kutsallığını kazanmasında onun biyolojik özelliklerinin ve yetiştiği ortamın etkili olduğunu düşünülür. Lotusa botanik açıdan yaklaşıldığında, doğada yer alan çiçeksi bitkiler grubundan olan bu çiçek, geniş su birikintilerinin bulunduğu coğrafyalarda yaşar. "Su üzerine çıan köklü bitkiler grubundan olan" (Şişli, 1980: 53) lotus; bataklık, sazlık, gölet gibi genellikle durgun suya sahip alanlarda yetişen, yapraklarındaki çeperleri sayesinde kir tutmayan ve kendisini dölleyerek var olan bir bitki türünü tanımlamaktadır. Kökleri ile dibe, yaprakları ile suya bağlı olan bu bitki Latince adı ile Nymphae familyasından gelmekte olup, yalnızca daha uzun gövde yapısı ve geniş yapraklarından dolayı nilüfer bitkisinden ayrılmaktadır. Bitkinin yüzeyinde yer alan çeperler, üzerinde kir tutmamasını sağlarken; lotur aynı zamanda hem dişil hem eril özelliği ile kendisini dölleyebilir. Bu özellikleri onun Doğu Felsefesi'nde kutsal bir bitki olarak görülmesini sağlar. H. P. Balvatsky'e "bu bitki, kutsal yeniden doğum ve evrende yaratılış arasında bir baştan çıkarıcılık sembolü olarak görülmektedir. Çünkü tohumları ile kendisini dölleme özelliğine sahip olan lotus, Hint ve Eski Mısır inançlarına göre yaratıcı tanrılarının doğduğu çiçektir" (Balvatsky, 1892: 191). Bu çiçeğin, özellikle Budistler için kutsal olmasının özelliği yine biyolojik özelliğinde yatar. "Mevsimler bir döngü içinde hareket ederken, çiçekler de açıp ölürler. Ancak bitkilerin pek çoğu önce çiçek açıp, çiçeklerini döktükten sonra meyve verirken, lotus meyvesi olgunken çiçek açar. Bu nedenle lotus Budist rahipler için geçmişin, şimdinin ve geleceğin bir aradalığına sahiptir" (Günay, 2009: 12). Bitkinin biyolojik özelliğinin yansımalarını ilk olarak mitolojide bulmak mümkümdür. Mısır hiyerogliflerinde "Şafakta sudan doğarak gece kendine kapanan güneşin bitkisi" (Balvatsky, 1892: 191) olarak tanımlanan çiçek bu yönüyle Güneş Tanrısı RA ile ilişkilendirilir. Sudaki ilk kaos ile Nun yükselirken, RA'nın ilk var olan olarak mavi lotustan doğduğu yine başka bir mitte RA'nın, henüz okyanusun derinliklerindeyken bir lotus tomurcuğunda hapsolduğu geçmektedir. Lotus, "dünyanın başlangııından önce güneş Toumou'nun 'Gel bana' çı̆̆lığını duyduktan sonra açılan çiçekten güneş diskiyle birlikte çıkmış ve dolayısıyla da büyük lotustan çıkan tanrı olarak bilinmiştir" (Joret, 1897: 260). RA'nın yaşam kaynağı olan lotus, tanrılar ve bu dünyadaki temsilleri firavunlar için yalnızca ruhani bir güç değil, aynı zamanda cinselliğin ve tutkuların bitkisidir. Bitki tüketildiğinde kısa süreli cinselliği arttırıcı etkiye sahiptir. Bu yönünü Seawight, Turin Papirüsleri'ndeki görsellerle ilişkilendirir: "II.Ramses döneminde kadınların mavi lotus bitkisi 
giyerek, kur yaptıkları gözlemlenir" demektedir (Günay, 2009: 11). Eski Mısır'ın ardından Hint mitolojisine bakıldığında Brahmanizm etrafında şekillenen öğretilerde yaratıcı tanrı Brahma, koruyucu tanrı Vişnu ve yıkıcı tanrı Şiva, mitlerde lotus çiçeğinin üzerinde oturarak temsil edilirler. Budist felsefede, ulaşılacak son mutluluk ya da cennet ülkesi olarak adlandırılan Sukhavati; lotus çiçeği üzerine kurgulanmıştır. Bu cennetin bulunduğu kutsal Meru Dağı çiçeğin ortasındaki dişil organı üzerine kuruludur ve onun özsuyu Budist insanın ruhunu temsil eder. Budist öğretilerle beslenen Hint Felsefesi'nde yer ve gök arasında bir köprü görevini üstlenen bu çiçek, Çin Felsefesi'nde ise ruhun dinleme alanıdır. "Kurumuş nilüfer yapraklarını oldukları gibi bırak, onlar bize sonbaharın ağııını anlatıyor" (Sarkowicz, 2003: 44) dizelerine de yansıdığı gibi doğanın sesine kulak veren bu uygarlık için lotus, Mahayana Budistleri'ne göre kadının bir güzellik kıstası olarak da görev yapar:

Geçmiş yüzyıllarda lotus pabuçlarının, Çinli kadınların güzelliğe ulaşmasında tek koşul olduğuna inanılırdı. Tang Hanedanlığı döneminde bir cariye, küçük ayakları ile altından yapılmış lotus platformu üzerinde dans ederek, sahip olduğu küçük ayakları ile imparatoru büyüler. Çinli kadınlar tarafından cariyenin imparatorun gözündeki değerinin, küçük ayaklara sahip olmasına bağlanarak, o zamandan itibaren genç kızların başparmakları kııııp sargılanarak, lotus ayakkabısı adı verilen küçük ökçekli ayakkabılar giydirilirdi. Altın lotus ya da ayak dondurma geleneğinin temeli akıllı ve güzel beden; acı çekerek olgunlaşan bedeni işaret etmekteydi. Ayakkabının altında bulunan lotus kabartmaları ise, kızın bitkiyle özdeşleştirilmeye çalışılan dişiliğinin temsili konumundaydı. Pabuçların doğaya dokunuşu ile oluşan motif lotus ile anlam bulmuştur (Günay, 2009: 17).

Çiçeğin biyolojik özelliğinden dolayı yapılan bu anlam yüklemeleri ile şekillenen mitler, günümüz sanatını da besleyen bir kaynağa sahiptir. Güncel sanatta kullanılan bir çiçeği temsil boyutunda irdelemek istediğimizde, bu çözümlemede her türlü anlam ya da tasdik toplumsal pratikler dâhilinde biçimlenir. Örneğin bir çiçek, ayna, kadın ya da rengin imgeye dönüşmüş hali, sanatta gerçeğinden kimi zaman bağımsız işleyebilir. Sanatta temsil boyutunda yer alanların, gerçek yerine farazi bir üretim olması da mümkündür. Sanat tarihçi Richard Leppert'in bu durumu şu cümlelerle belirtir:

İmgelerin temsil ettiği şey, sadece kuruntu, arzu, rüya ya da fantezi dünyası olabilir (...) İster fotoğraf, ister film ya da video, isterse de resim olsun, imgelere baktığımızda gördüğümüz şey insan bilincinin ürünüdür. İnsan bilinci de kültür ve tarihin ayrılmaz bir parçasıdır. Bu bakımdan imge, maden cevheri gibi kazılarak çıkarılan bir şey değil, belli bir sosyokültürel ortam içerisinde belli bir işlev görmesi için inşa edilen şeydir (Leppert, 2002: 14-22).

Kısacası sanatta üretim dinamiklerinin inşası tarih, coğrafik konum, toplum ve bireyler dâhilinde olduğundan temsilin de yansız olması düşünülemez. Dolayısıyla bu açıklamayı dar alana indirgeyip lotus gibi bir imge üzerine konuştuğumuz zaman, mitlerde onun adına atfedilmiş olan anlam inşalarına dokunmadan çağdaş sanattaki yerini sorgulamak temelsiz olabilir. Lotusun sunumları üzerine konuşurken ve onun şifrelerini çözmeye çalışıken ister istemez toplumsal pratiklerin ürettiği yakıştırmalar dâhilinde çağdaş sanattaki yorumlarına bakılmalıdır. Aynı zamanda araştırmanın çerçevesini sınırlamak açısından, eserlerini doğada var olanlar özellikle egzotik bitkiler üzerine kurmuş olan Ruud Van Empel ile sınırlı tutulmuştur. Bununla birlikte sanatçının çalışmaları reşit olmayan çocukların çıplak ya da yarı çıplak görüntülerinden oluştuğu için makalede bu görsellere yer verilmeden çözümlemeler yapılmaya çalışılacaktır. Bitki evren, sanatçının üretim sürecinde öteki, kimlik, aidiyet, dişil-eril, sorgulamalarıyla var kılınır. Empel'in fotoğraf ve dijital ortamda oluşan eserleri, görüntünün manipüle edildiği, sınırsız ve canlı renk ilişkileridir. Kendisi bitki evrenin mimetik bir temsilini yaratır. "Mimetik biçimin tipik özelliği, seyircinin en azından ilk bakışta imgeyi aslında temsil ettiği şeyin ta kendisi olarak algılanmasına yol açan olağanüstü doğalclığıdır" (Leppert, 2002: 38). Empel bu doğalclığı en ileri noktaya taşırken; tıpkı Hieronymus Bosch, Rachel Ruysch, Peter Brueghel gibi Flemenk atalarınından aldığı ayrıntıya olan düşkünlüğü ile karşımıza çıkar. Dijital kolaj tekniği ile oluşan eserler, özellikle tropik ormanların ve sulak bölgelerin içinde yer alan çocuklardan oluşur. Bu çocukların suda yer alışları ve bakışları ile izleyici kendisini tekinsiz bir ruh hali içerisinde bulur. Empel'in son dönem serilerinden olan Evren ve Venüs, doğanın en dipsiz ve yeşil alanlarında, lotus bitkisinin çevresinde konumlanan kimi zaman yalnız kimi zaman ise birkaç çocuktan oluşur. Serilerde ortak olan husus, yabanıl doğanın içinde tedirgin bakışlı, etnik kimliğe sahip çocukların seçilmiş olmasıdır.

Bu gölet ya da su birikintisi, çocuk bedenlere ve lotuslara ev sahipliği yaparken, bunu doğanın küçük olanı kuşatması olarak da görmek mümkündür. Doğanın içinde tek başına yer alan çocuklar bizi adeta Alman asıllı Jacob Grimm (1785-1863) ve Wilhelm Grimm (1786-1859) ya da Grimm Kardeşlerin fantastik öykülerinin bir sahnesine taşır. Bir Alman köyünde yaratıklar tarafından kaçırılarak, ormanın derinliklerinde hapis olan çocukları konu edinen Changelling/ Değişen adlı masalın alt katmanı olan vahşi doğa, çocuk bedenler ve onlara yüklenen yabanıl cinsellik, Empel'in fotoğraflarında da temel noktalardır (Günay, 
2009: 60).

Grimm masallarında, ergenlik öncesi çocuk kaçırma geleneği sıklıkla, onun saflığından faydalanma ve reşit olmamış temiz kanından beslenme düşüncesi gibi groteks, şiddet ve tekinsizlik duygularını izleyiciye hissettirir. Çocuğun kendi yaşam alanın dışında kodlandığı bu tekinsiz ruh hali, Empel'in kayıp karaterlerinin de dayanak noktasıdır.

Doğanın sakin ve bakir alanlarında çocuklar masumiyet ve saflığın temsilidirler. Bu saflık sanatçı için cennet düşüncesi ile bir tutulur. "Manzara, çocuklar, hayvanlar, orman, yabani olan (...) Büyük olasılıkla sanatçı cennetini yaratmakta ve onun bu seçiminde arzu yer almaktadır, bilinçsiz bile olsa bu kurguları ortaya koyan şey arzu olmalı, cennetin arzusu..." (Heuvel, 2015: 21). Bu noktada cennet arzusu, zenci çocukların bir mabedi gibi duran su ve geniş lotus gövdeleriyle ilişkilendirilir. Lotusu mitlerde, tanrıların doğduğu çiçek anlamıyla düşündüğümüzde, Empel'in cennet arzusu düşüncesini, lotusu seçerek kuvvetlendirdiği görülür. Su, lotus ve çıplak beden üçlemesi üzerinden imgelerin işlevlerine doğru gidildiğinde, ilk olarak bakmak istediğimiz Venüs/ Venus isimli dijital kolaj seridir. Bu seride beyaz tene sahip bir kız çocuğu, doğanın ve insanın ilk tözü olan suda anlam bulur. Suyun dişil olan özelliği, Bachelard'ın şu cümlelerinde ifade bulur: "Lekesiz tertemiz bir su elde etmek istiyorsanız içine bakireleri atın" (Bachelard, 2006: 134). Bu açıdan, lotus ve kız çocuğu suyun saflık derecesini düşünsel olarak arttırır. Bu iki gösterge ile saflık kavramı sorgulanmakla birlikte, farklı açılımlar yapmak istediğimizde, seride dişil olana da kapılarını açan bir anlatım dili tercih edilmiştir. Çiçek açmak; yazın gelişinin ve doğanın uyanışının habercisi ise, felsefi olarak dişil olanın sunumudur.

Dil bilimsel bir yaklaşımla "Bir tomurcuk ve müjdeci olan çiçeğin İngilizce'dek başlıca anlamlarından biri 'öz'dür (essence). Hem Latince hem de Fransızca'da çiçek açmak (bloom) gibi zaman zaman yüzey (fleur d'eau gibi) anlamına gelir. Bunun altında yatan mantık, çiçeğin üreme organın olması ve bu amaca göre renklenip kokulanmasıdır; dolayısılla; teşhir edilen şey aynı zamanda bir üreme organıdır. Yüzey aynı zamanda özdür ya da meyveyi ve tohumlarını ortaya çıkardığ zaman öyle olur. Belki de çiçeğin tenasülle olan bu ilişkisi nedeniyle kadınların adet görmeyle ilgili aktivitesine çiçekler (flowers) adı verilmiştir yine bir bakirenin bekaretini kaybetmesi (deflowing) dir" (Goody, 2010: 30).

Empel'in çiçeklerinde açık ya da örtük biçimde sıkça ortaya konulan cinsellik, beyaz tenli bakışları izleyiciye dönük çıplak bir imge ile birleşir.
Bu anlamıyla lotus saflığın yanında henüz yaşanmamış cinsel arzuların da teşhiridir. Cinselliğin kodları ise ikisinin de ait olduğu suya dayanır. "Su tuykuyla mırıldandığı anda, suların analığa tapınma duygusu tutku ve içtenlik ortaya çıktığında süttür artık..." (Bachelard, 2006: 134). Venüs'e Jungcu yaklaşımla eğildiğimizde su; bilinçaltının yaratıcı simgesidir ve dişil olan ile özdeşlik taşır. Dişil olan yaşam suyunun kaynağıdır. Empel'in bu serinde seçimi olan çıplaklık, sanatsal bir temsil kategorisi olarak belirirken, Berger çıplaklık kavramını şu sözlerle ifadeler: "Kadının çıplaklığı bizzat kendi duygularının ifadesi değildir, aksine sanat eserinin sahibinin duygu ve taleplerine teslimiyetin göstergesidir. Soyunuk olmak tek başına olmaktır; fakat çıplak olmak ise başkaları tarafından görülmek ve kendisini tek başına olarak algılamamak demektir (...) Soyunukluk kendisini kendine açar. Çıplaklık ise sergilenir" (Berger, 1972: 52, 54). İmgenin kimin iktidarına sunulduğu sorunu açısından Empel'in kurgularına benzer bir yaklaşım sergileyen sanatçılardan Çinli fotoğraf sanatçısı Ren Hang (19872017), eserlerinde etnik kimliğe sahip olan bireyleri seçer. Pornografik bir anlatım diline sahip olan sanatçının çıplak bedenler ve lotus ile baskın kıldığı kurgularında, fetiş bir nesne olarak yer alan Uzak Doğulu kadınların bakışları izleyiciye dönüktür.

Empel'in gün ışığıyla beslenen eserlerine rağmen Hang fotoğraflarını gece ile birleştirir ki bu durum suyun şeffalığını da elinden alarak tekinsizlik katmanını arttıır. İzleyici kameranın ışığı ile bu kadraja katılır. Doğurganlığın, saflığın ve cinselliğin temsili iri lotus dalları, bedenleri örtmekte ya da başka bir okuma ile bedenle bakıs arasına mesafe koymaktadır. Bu mesafe ise görünmeyene olan arzuyu körüklemektedir. Bu noktada sanat tarihçi Zeynep Sayın; "kendisiyle göz arasına mesafe koyan bir imge, gözle yetinmeyerek dokunulmak istenmektedir" (Sayın, 2003: 62) sözü ile sanat eserindemesafenin kadının gizeminive muammasını arttırdığı görüšündedir. Bedenler bir daire oluşturarak lotusu merkeze alıp bütünleşirler. Doğu kültürünün kutsal saydığı bir çiçek ve etnik kökenli kadın adeta toplumsal ve kültürel kodlamalardır. Bu kodlamalar bir anlamda Batı'nın öteki olana atfettiği erotik, gizemli olana da kapılarını açar. Leppert'e göre, “Ötekinin fiziksel bedeninin kaçınılmaz olarak uyandırdığı farklıık konusu Batı'daki görsel sanatlarda yüzyılllar boyunca olağanüstü çekici bir anlam olmuştur" (Leppert, 2002: 269). Bu ifadenin söylem etkisi açısından yarattığı imaj aynıdır: 'egzotiklik'... Bir çiçeğe ve bedene indirgenen egzotiklik... Hang'in eserlerinin temel dayanağı; çıplaklığın toplumsal tabuların yıkma düşüncesidir. Nitekim, Batılı bir izleyici için sanat tarihinde yüzyıllar 
boyunca öteki olarak söylem diline kodlanmış olanlar, bu kodlamalarını devam ettirirler. Hang'de şahit olduğumuz etnik olan kavramı, Empel'e döndüğümüzde özellikle zenci çocuklar üzerinden irdelenir. Renk toplumsal olarak bir göstergedir ve içerisinde kültür hiyararşisi barındırır. Bu kültürel kodlamaları kullanan Empel, World/ Dünya Serisi'nde karşımıza zenci çocuklar ile çıkar. Lotus ve zenci çocuklar gerçek gizemli ve tetikleyici bir bakış açısına kapılarını açarlar. Zenci çocuğun bakışı, fotoğrafın şahitlenmek isteyen anlık görüntüsünü elinden alarak sürekli yaşanılan tekinsiz bir hal ile izleyiciyi baş başa bırakır. Vahşi doğa arasında gizlenen çocuğun bakışı; kendisine yabanıl ve egzotik bir temsili de katar: lotus.

Yine Leppert'in şu savı zenci çocuklar ve lotus üzerinden düşünülebir: "Derisinin rengine indirgenen şey egzotik olandır. Renk farklılığı tanımlar, arzuyu körükler, bedenlere olan iştahı arttırır. Ayrıca renk bir kültür hiyerarşisine işaret eder ve bunu da Batılı resim geleneğinin uzun tarihine yaptığı açık göndermelerle yapar" (Leppert, 2002: 271). Empel, Batı sanat geleneğinin Oryantalist bir bakış açısı ile yaklaştığı eserlere kimi zaman bir tepki olarak, zenci çocukları ele aldığını belirtir. Saflığın yalnızca beyaz çocuk bedenlerinde temsil edilen durumuna ve ikonografik sanat belleğimize karşı bir duruş olarak zenci çocukları kullanan sanatçı, buna rağmen sunumlarının alt okumalarında karşımıza çıkabilecek Oryantalist bir yaklaşıma da engel olamaz. Nitekim sanatın inşası boyutunda gerek sanatçı gerek ise izleyici yanlı bir bakış açısıyla hareket eder. "Sanat eserleri, alııılara mütemadiyen aynı sinyali ya da sinyal kümesini gönderen radyo-televizyon vericileri gibi değildir. Anlam hem kullanıcı hem de yaratıı tarafından dinamik olarak inşa edilir. Anlamın inşası, nesnelerin tarihsel ve toplumsal özgül koşullar altında harekete geçirdiği bitimsiz bir üretimdir" ( Leppert, 2002: 21). Bu anlamda Empel'in seçtiği imgeler üzerinde konuştuğumuzda, öteki olma durumlarını devam ettirmekte oldukları söylenebilir. Empel, eserlerinde çocuk imgesini hangi bağlamda kulandığını şu sözleri açıklar:

Henüz tam büyümemiş, karakterleri yerine oturmamış insanlar. Çocuklar birbirlerinin aynısıdır. Bu ayrılık sayesinde ben onları sembol gibi kullanabiliyorum, masumiyeti temsil etmeleri gibi., bununla birlikte çocukların bir karanlık tarafı vardır. Benim de anlatmaya çalışı̆ğım dünyada güzel görülen herşeyin tehlikeli olabileceği. Doğayı ele alın, cennet gibi görülüyor olmasına rağmen vahşi bir orman. (Empel, 2011: 51).

Empel, yine zenci çocuk üzerinden kurduğu Moon/ Ay Serisi'nde izleyiciyi mitlere taşımaktadır. İsis ve Osiris'in oğlu olarak lotusun içinde dünyaya geldiğine inanılan Horus'un (Harpocrates) çocukken bu çiçeğin taç yapraklarında geceleri gizlendiği mitlerde yer alır. Lotus ve çocuk arasındaki ilişkiyine çiçeğin biyolojiközelliğine dayanır. "Kendisiniyeniden üretebilecek tohuma sahip olan bu bitkinin uzun sapı; çocuğun göbek bağı, yaşadığı Nil Nehri ise İsis'in döl yatağı olarak düşünülmüştür. Nil suyunu İsis'in döl yatağı ve bitki kökünün de plasenta olarak görülmesi, Eski Mısır mitlerinde, bitkinin çocuğun taşıyıcı olarak temsil edilmesini sağlar" (Günay, 2009: 64). Bu noktada eleştirmen, şu yorumda bulunur: "Başının üstünde bir hale gibi yer alan lotus çiçeği ile suyun ortasında tıpkı bir dini törendeymiş gibi elleri göğüs kafesinin üstünde yer aldığını belirtir" (Heuvel, 2009: 31). Kutsal bir çiçek gibi çocuğun başının üstünde yer alan lotus, yaydığı ışık ile onu hem belirgin kılmakta hem de koruduğunu göstermektedir.

\section{Sonuç}

Sonuç olarak, lotus ya da nilüfer bitkisi yalnızca doğada var olan bir canlı olmasının ötesinde mitlerde sıklıkla rastlanan bir çiçektir. O'nun sanattaki bu yolculuğu yalnızca mitlerle sınırlı kalmamış ve çağpdaş sanata da yansımışıtır. Özellikle Doğu kültüründe geniş yer tutan bu çiçek dolayısıyla oryantalist bir nişane olarak sanat eserinde yer alır. Oryantalist bakış açısının temel düşüncesi, Batı'nın Doğu'yu yönetilmesi gereken, hayalci, romantik ve egzotik olarak gördüğüdür. Batı'nın ötekinin kültürüne ve yaşam biçimine yönelik tutumunda, O'nun hızla tüketim odaklı haline gelen yapısını yatar. Kendi açılımı genişetmek için Doğulu olana yönelen Batı, öteki olanı sanatına yansıtır. Öteki onun için, yeni bir ütopya ve gelecek için bir sığınak kurma alanıdır. Öteki olanla, kendi ideolojik ve kültürel ağına soluklanma alanı katmak isteyen bu düşünce, Doğunun kutsal olarak gördüğü değerleri de kendisine ekler. Bu noktada her daim fantastik yaratıklar, gizemli, doğaüstü güçler ve dişil olanla iliştirilen Doğu'nun, mitlerle beslenen zenginliği, Batı için bir egzotiklik göstergesidir. Bu gösterge olma özelliğini kazanması çiçeğin biyolojik özelliğinden ileri gelir. Çiçek, tohumları ile kendi döllemesi ve yüzeyinde kir barındırmaması sebebiyle Doğu kültüründe kutsal kabul edilmiştir. Empel'in eserlerinde egzotik olan bu çiçek ve etnik kimliğe sahip çocuklar ile ifşa edilir. Çocukların izleyiciye olan bakışları ve ten renkleri ile hem cinsiyet hem de kimlik tartışmalarını beraberinde getirirler. Mitlerde dişil ve yaratıcı olan olarak kodlanan lotus, kendi yaşam alanına çocuk bedenlerini de dâhil ederek, çift katmanlı bir arzu edimi yaratır. İktidarın resme bakan gözlerde olduğu ve resimde yer alanların seyirlik bir nesne olarak var kılındığı Empel'in üretim sürecinde, kendisi bu hiyerarşik anlayışı yıkmak istese de gerek renklerin parlak ve göz alıı̆ğı, gerekse, çocukların 
sunum tercihleri açısından tuzağa düşürücüdür. Nitekim, ister adına öteki, isterse de egzotik olan kavramları kullanılsın, bu tercih; bir kurgudur ve bu sanat nesnesi fiziksel olarak değil yalnızca zihinsel olarak erişilebilen bir dünyanın kapılarını izleyiciye açar. Bu egzotik cennet, yalnızca fantaziyle ulaşılabilen, onun dışında ulaşılamayan bir ütopya, bakışla yetinebilen bir temsil alanıdır.

\section{Kaynakça}

Bachelard, G. ( 20/4). Mekanın Poetikası (çev. A. Tümertekin), İstanbul: İthaki Yayınları.

Berger, J. ( 1999). Görme Biçimleri (çev. Y. Salman), İstanbul: Metis Yayınları.

Blavatsky, H.P. (I 888). The Secret Doctrine, The Synthesis of Science, Religion and Philosophy, Theosophical University Press.

Empel, R.V. (20II). Ruud Van Empel Photoworks 1995-20I0, PhotoWorks International BV.

Goody, J. (20।0). Çiçeklerin Kültürü (çev. M. Beşikçi), İstanbul: Ayrıntı Yayınları.

Günay, B. (2009). Bitki Evreninden Bir Gösterge Olarak Lotus ve Sanatsal Temsilleri, Yayınlanmamış Sanatta Yeterlik Tezi, Marmara Üniversitesi Güzel Sanatlar Enstitüsü, istanbul.

Heuvel, M. (2009). Ruud Van Empel Photoworks 2006-08, PhotoWorks International BV.

Leppert, R. (2009). Sanatta Anlamın Görüntüsü / Imgelerin Toplumsal İșlevi (çev.i.Türkmen), İstanbul: Ayrıntı Yayınları.

Sarkowich, H. (1998). Bahçelerin ve Parkların Tarihi (çev. E. Kayaoğlu). İstanbul: Dost Kitabevi.

Sayın, Z. (2003). Imgenin Pornografisi, ìstanbul: Metis Yayınları.

Stein, R. B. (198I). Charles Willson Peale's Expressive Design: The Artist in Hits Museum içinde prospects: The Annual of American Cultural Studies 6.

Şişli, M.N. (1980).Ekoloji, Ankara: Hacettepe Üniversitesi Yayınları.

Wheelock, A. K. Jr. (1989). Stiil Life: Its Visual Appeal and Theoretical Status in the Seventeenth Century, Washington, D.C.: National Gallery of Art. 